\title{
Supply Chain Management in the Aquaculture Industry: The Case of Food Fish Aquaculture in Sri Lanka
}

\author{
S.P.M. Jayantha ${ }^{1}$ and D.A.M. De Silva ${ }^{2}$
}

${ }^{1}$ National Aquaculture Development Authority of Sri Lanka, 756, Base Line Road, Colombo 10.meth_lk@yahoo.com

${ }^{2}$ Department of Agribusiness Management, Faculty of Agricultural Sciences, Sabaragamuwa University of Sri Lanka, P.O. Box 02, Belihul Oya.desilva.achini@yahoo.co.uk

\begin{abstract}
The study was taken up with the objective of identification of local and regional market potential for each main food fish species commonly found in the catch of inland fisheries and aquaculture in Sri Lanka and to identify the market segmentation of each of these fish species and prices in local and regional markets. The study methodology included both desk research and primary research in landing sites and regional markets of Western, Eastern, Sabaragamuwa and North-Central provinces in Sri Lanka. The study has employed BCG matrix for interpretation and analysis the supply chain. The study identifies the different value chains present in the trade map. Fishery value chain is dominated by few big players and a number of intermediaries were high and hence adds up to the cost of product without adding value to the chain. Presence of "patron-client relationship" throughout the supply chain is prevalent. The research indicates that the demand for fishe in the regional markets is dominated mainly by few preferential species.
\end{abstract}

Key words: supply chain, fish and fishery products, Sri Lanka

\section{Introduction}

Aquaculture continue to play a growing role in Sri Lanka's economy with growing sophistication in small business supply chain networking that links fisheries, marketing and transportation. Sri Lanka is endowed with rich natural and man made reservoirs and tanks and the country is blessed with wide variety of aquatic species. This gift of nature complements the customs and traditions of the communities, which understands that the vast natural resource is the key to their prosperity and social development. Sri Lanka has immense water resources, both fresh and brackish water bodies. It has 2905 sq. Km of inland water resources which is available for aquaculture and about 190524 ha of brackish water resources mainly utilizeed today for prawn and shrimp farming (National Aquaculture Development Authority, 2009). 
The employment generated from seasonal village tank fish culture is estimated to be around 6000 of which 13 percent are women (Siriwardena and Jayakody, 2003). It was estimated in 1999 that the shrimp aquaculture industry provided approximately 40000 jobs both directly and indirectly, which represents 11 percent of the total employment in the fisheries sector (Siriwardena, 1999). However, the previously estimated figure of 20000 directly employed as a result of shrimp farming has currently been reduced to 8000 due to the repeated occurrence of disease within the shrimp industry. The participation of women in shrimp aquaculture is around 5 percent of the total workforce (Siriwardena and Jayakody, 2003). An estimated 2500 people are engaged in the production and breeding of ornamental fish (Haputanthri et al., 2001) of which around 30 percent are estimated to be women, however, no thorough survey has been carried out on this aspect (Siriwardena and Jayakody, 2003).

Supply status has been changing drastically through out the year and depends highly on the availability of rain. Consumption behavior affects badly on the changing the supply of aquaculture fish to the domestic market. In general, people in rural areas used to consume more freshwater fish, compared to coastal communities. Only a handful of researchers paid attention on supply chain management of Sri Lankan fisheries and this study aims to investigate the supply chain management in aquaculture industry. This paper reviews the peculiarities of the supply chains in the fishing industry with its highly fluctuating raw material supply and stringent quality demands.

\section{Study methodology}

The study supply chain analysis of aquaculture industry of Sri Lanka has been structured to capture the essence of the process and flow of the value chain in aquaculture. The framework of the study will help to understand the levels of supply chain, its role and importance, the cost of operation, the barriers to entry, mobility and exit, the economies of scale, the effect of market forces viz the demand and supply forces. The study has been designed to map the key processes and flows in the supply chain of aquaculture in the local market.

\section{Research framework}

The frame work employed in the research "supply chain analysis of aquaculture" in Sri Lanka is a stratified frame work in which the stake holders are employed on the horizontal axis of inquiry and the various concerns and 
issues processes and flows are on the vertical axis. This frame work is designed to map the entire supply chain across levels of the supply chain and to bring them on a common axis to induce a complete and holistic understanding of the chain.

\section{Tools and Techniques}

The study has adopted various tools and techniques for collection of information on various aspects. A thorough desk review was undertaken to develop insights into the key areas that needs to be focused during the primary research and discussions were held with various experienced persons in the fishery sector to collect information related to the issue on hand. Primary research was conducted in the West coast for prawn and shrimp farming, Sabaragamuwa province (Udawalawa reservoir), Eastern province (Iginiyagala and Ampara reservoirs) and North-Central province (Parakkrama Samudraya, Mahavilachiya and Minneriya reservoirs) to collect first hand information on the specific parameters developed on the basis of the study. In the primary research, both qualitative and quantitative approach has been adopted. In depth interviews were conducted to obtain information from the key respondents on the issues and concerns of the supply chain of aquaculture in the study area. Different semi-structured questionnaires were prepared for the purpose and were used as tools of research. Various group discussions were arranged between the fishermen as well as the different players of the supply chain. These discussions were useful in finding out the different aspects of supply chains for aquaculture. It also helped in validating the information collected by the individual investigators through face-to-face interviews with individuals or otherwise. Instruction moderating schedules were used as tools for the purpose. Observation were keenly made during the course of group discussions and documented. While interviewing the respondents, observations were gathered from their reactions. The investigators' impression from their own experience during course of investigation was also taken as part of the observation. The observation was quasi-participant type. Operations of the activities, the manner of functioning of various players of the value chain at different levels was observed. These observations formed an essential part of the entire filed work. The study on supply chain analysis of aquaculture in Sri Lanka was conducted according to the preferential sampling of the researcher. The selection of the study area was on the basis of importance of the production and landing center, the number of fishermen at the landing center, the volume of trade granted, etc. 
The regional markets were selected on the basis of the size of the operation, number of forward and backward linkages, the volume of daily trade, etc. The places covered were mainly the landing centers in West coast, NorthCentral, East and Sabaragamuwa provinces. These landing centers were both inland landing centers and brackish water landing centers. The major regional market for fishing was covered during the study to develop a good understanding of the food fish aquaculture supply chain. The study sampling has been done to incorporate all the stake holders in the study and hence helps to produce a complete picture of the fishery value chain.

The "fishbone diagram" is an analysis tool that provides a systematic way of looking at effects and the causes that create or contribute to those effects. Because of the function of the fishbone diagram, it may be referred to as a cause-and-effect diagram. The value of the "fishbone diagram" is to assist teams in categorizing the many potential causes of problems or issues in an orderly way and in identifying root the causes.

The process of construction of fish bone diagram consists of following steps (NCDENR, 2002).

1. Draw the fishbone diagram

2. List the problem/issue to be studied in the "head of the fish".

3. Label each "'bone" of the "fish". The major categories typically utilized are:

- The 4 M's: Methods, Machines, Materials, Manpower

- The 4 P's: Place, Procedure, People, Policies

- The 4 S's: Surroundings, Suppliers, Systems, Skills

4. Use an idea-generating technique (e.g., brainstorming) to identify the factors within each category that may be affecting the problem/issue and/or effect being studied. The team should ask, "What are the issues affecting/ causing..."

5. Repeat this procedure with each factor under the category to produce sub-factors. Continue asking, "Why is this happening?" and put additional segments for each factor and subsequently under each sub-factor.

6. Continue until you no longer get useful information as you ask, "Why is that happening?" 
7. Analyze the results of the fishbone after team members agree that an adequate amount of detail has been provided under each major category. Do this by looking for those items that appear in more than one category. These become the "most likely causes".

8. For those items identified as the "most likely causes", the team should reach consensus on listing those items in order of priority with the first item being the most probable" cause.

\section{The BCG matrix for fishery}

The BCG matrix (Boston Consulting Group analysis) is a chart that had been created by Bruce Henderson for the Boston Consulting Group in 1970 to help corporations with analyzing their business units or product lines (Mercer, 1993). Cash cows are units with high market share in a slowgrowing industry (Mercer, 1993). These units typically generate cash in excess of the amount of cash needed to maintain the business. Dogs are units with low market share in a mature, slow-growing industry (Mercer, 1993). These units typically "break even", generating barely enough cash to maintain the business's market share. Question mark is growing rapidly and thus consumes large amounts of cash, but because they have low market shares they do not generate much cash (Mercer, 1993). The result is large net cash consumption. A question mark has the potential to gain market share and become a star, and eventually a cash cow when the market growth slows. If the question mark does not succeed in becoming the market leader, then after perhaps years of cash consumption it will degenerate into a dog when the market growth declines. Stars are units with a high market share in a fast-growing industry. The hope is that stars become the next cash cows (Mercer, 1993). Sustaining the business unit's market leadership may require extra cash, but this is worthwhile if that's what it takes for the unit to remain a leader. When growth slows, stars become cash cows if they have been able to maintain their category leadership.

\section{Study locations}

Figure 1 is showing the study locations in the map of Sri Lanka. 


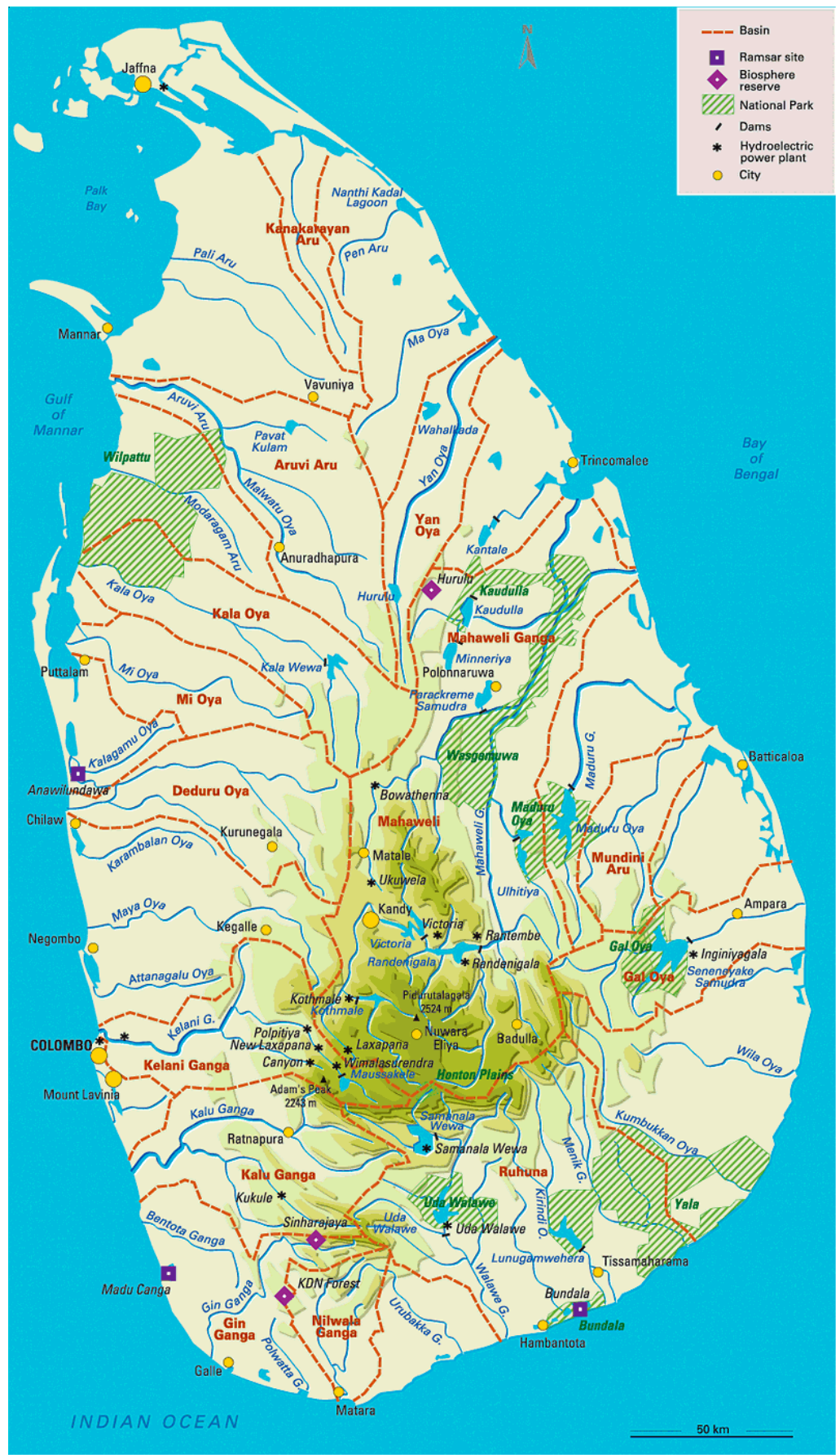

Figure 1: Map of the major inland fish and aquaculture landing sites and research locations; (Source: Ministry of Fisheries and Aquatic Resources) 


\section{Results and discussion}

\section{Components of the fishery}

Aquaculture in Sri Lanka can be classified according to the nature of the operation i.e. capture and culture. The major components of aquaculture are as follows: fresh water fishing (a. perennial water bodies b. Tanks) and Fish culture (a. Tanks b. Ponds c. Ornamental fisheries).

\section{Fresh water fishing}

Freshwater fishing is based on the inland water resources and is an important source of protein supplement in rural diet. The inland water has been exploited for its aquatic resources by the communities to meet their food requirements and also is a means of livelihood to many. Figure 2 brings the time series analysis of inland fish of Sri Lanka.

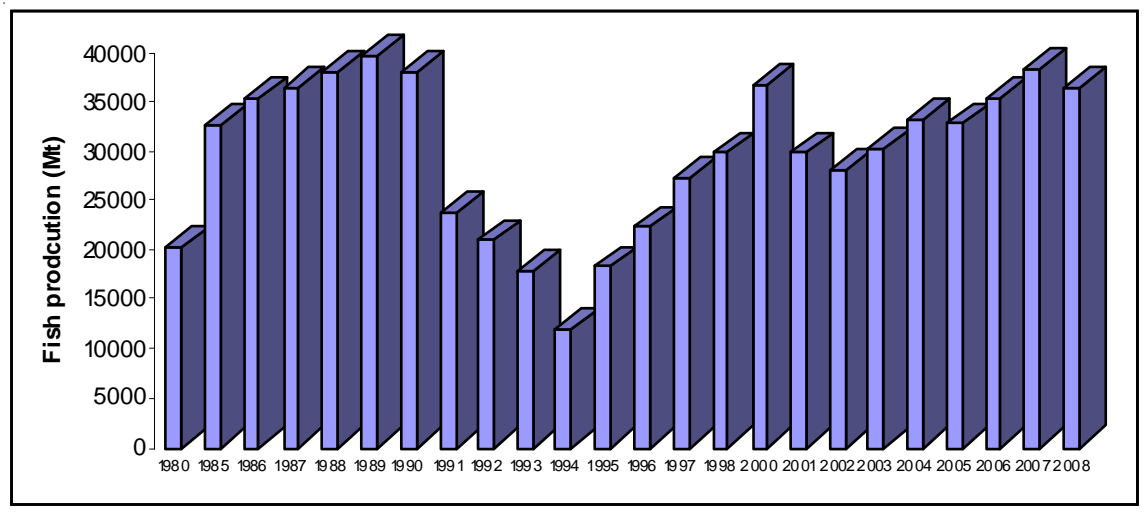

Figure 2: Inland and aquaculture fish production

Source: Ministry of Fisheries and Aquatic Resource Development

Table 1: Resource Profile of Inland Fisheries

\begin{tabular}{|l|l|}
\hline Resource type & Area $($ Ha) \\
\hline Major reservoirs & 70,880 \\
\hline Medium reservoirs & 19,004 \\
\hline Minor reservoirs & 39,271 \\
\hline Other new reservoirs & 25,000 \\
\hline Hill country reservoirs & 8097 \\
\hline Seasonal tanks & 100,000 \\
\hline
\end{tabular}

Source: National Aquaculture Development Authority of Sri Lanka 


\section{Market and product segmentation}

Segregation of product and market into district segments provide insight to compare the value chain, keeping in focus the product and market characteristics and find out uniqueness. Segmentation classifies people into groups based on shared characteristics (Sanyal and McLaughlin, 1993). Market segmentation is a selection of groups of people who are most receptive to a product.

The segmentation of the market is done on demographic variables such as age, sex, race, income, occupation, education, household status and geographic location and psychographic variables such as lifestyle, activities, interestsand opinions, product use patterns, product benefits.

The segmentation of the aquaculture species has been done on the basis of the demand of the various species in different markets. Market segregation is an indicative categorization based on the cumulation of price, availability, demand of the specific species in the market. Table 2 gives the market segmentation of important aquaculture species.

Table 2: Preferential Ranking of Species - Market Wise

\begin{tabular}{|l|l|l|l|}
\hline $\begin{array}{l}\text { Name of the fish } \\
\text { Species }\end{array}$ & $\begin{array}{l}\text { Local } \\
\text { Market }\end{array}$ & Regional Market & Export Market \\
\hline Prawn & $* * *$ & $* * *$ & $* * *$ \\
\hline Mud crab & $* * *$ & $* * *$ & $* *$ \\
\hline Tilapia & $* * *$ & $* * *$ & $* * *$ \\
\hline Common carp & $* *$ & $*$ & $*$ \\
\hline Cat fish (local) & $* * *$ & $* * *$ & Nil \\
\hline Big head carp & $* *$ & $* *$ & Nil \\
\hline Silver carp & $*$ & $*$ & Nil \\
\hline Rohu & $*$ & $*$ & Nil \\
\hline Hirikanaya & $*$ & $*$ & Nil \\
\hline
\end{tabular}

\section{Local market}

Local markets are essentially the markets near the landing centers (in the periphery of $25-30 \mathrm{Km}$ accessible by foot cycles and motor cycles), which include villages, sub divisions and nearby towns. The demand in these markets 
is generally stable except for the deviations during special occasions e.g. wedding ceremonies, festivals, alms giving, etc.

The main characteristics are as follows;

1. Demand for the average to low value product is based on the availability

2. Purchasing power of the consumer is the limiting factor for consumption of high value product

3. Number of vendors is limited

4. Demand for the aquaculture species is limited due to food habits of the community. Only limited species are in demand

5. Demand for the marine fish is higher than the inland fish

6. High value product rarely enters the local market

7. Demand is affected by the socio-cultural and the religious prohibitions to the extent that the market closes due to absence of the buyers from the market

8. The cost of operation is low as the product is consumed

\section{Regional market}

Regional markets are the bigger markets situated in the state capitals, large cities or metropolitan cities with variegated supply and demand linkages. The number of operators, limited is higher than local markets. These markets normally cater to a larger geographic location and the volume of trade is high. The number of buyers is high as compared to the local market

The characteristics of the markets are;

1. Serves as a channel to cater to up-country markets and distant markets

2. Serves as a connecting channel with the retailer, end user and the producer

3. More capacity to absorb the gult in the supply due to high number of demand channels

4. Price fluctuation is high and can happen on a daily basis depending on the demand of the larger market for the product

5. Purchasing power of the end consumers is higher than that in local markets 


\section{Product segmentation}

Product segmentation is the process through which products having similar affinity and nature cluster together and follows almost the same line of growth, cater to the similar kind of market and behave in a similar way under the forces of demand and supply. In this study the value of the product can be distinctly classified in four value slabs, i.e. export value product, high value product, av. value product and low value product. Table 3 presents the inland fish catch by major species and Table 4 brings average fish prices of various product segments.

Table 3: Inland fish catch by major species (Mt)

\begin{tabular}{|l|c|r|r|r|r|l|}
\hline Species & $\mathbf{2 0 0 0}$ & $\mathbf{2 0 0 3}$ & $\mathbf{2 0 0 4}$ & $\mathbf{2 0 0 5}$ & $\mathbf{2 0 0 6}$ & $\mathbf{2 0 0 7}$ \\
\hline Thilapiya & 23150 & 17870 & 22190 & 21620 & 19320 & 22510 \\
\hline Carps $^{1}$ & 9190 & 9050 & 5420 & 6130 & 9560 & 7630 \\
\hline Local $^{2}$ & $* * *$ & $* * *$ & 3190 & 3210 & 3930 & 4660 \\
\hline $\begin{array}{l}\text { Cultured } \\
\text { prawns }\end{array}$ & 4360 & 3360 & 2380 & 1870 & 2480 & 3580 \\
\hline Total & 36700 & 30280 & 33180 & 32830 & 35290 & 38380 \\
\hline
\end{tabular}

Source: Ministry of Fisheries and Aquatic Resource Development

Table 4: average prices for various product segments

\begin{tabular}{|l|l|l|}
\hline Product segment & Product & Av. Price/Kg/L KR \\
\hline Export value product & Prawn & $600.00-700.00$ \\
\hline High value product & Prawn & $500.00-600.00$ \\
& Tilapia & $150.00-170.00$ \\
& Carps & $130.00-140.00$ \\
\hline Average value product & Prawn & $400.00-500.00$ \\
& Tilapia & $110.00-140.00$ \\
& Carps & $110.00-130.00$ \\
\hline Low value product & Prawn & $350.00-400.00$ \\
& Tilapia & $100.00-120.00$ \\
& Carps & $100.00-110.00$ \\
& & \\
\hline
\end{tabular}

Source: Field survey-February 2009. 


\section{Export value product}

Export value products appear in two qualities i.e. higher value export markets such as European Union, United States of America and Japan, and lower value export markets such as China, Singapore, Hong Kong and Thailand. The products in this category undergo value chain with very high cost of operation and hence the profit margin of this segment is very high. The products undergo a standard processing procedure according to the specified international regulations for it. The operation is normally taken up by the processing plant owners and the exporters. Processors have to follow ISO, FDA, EU and HACCP norms together with special buyer considerations. In general, processors are operating their own production sites and they are acting as main feeders to supply channel. The value chain is dominated by the export/processing houses. The value chain of this segment is more organized as compared to other products because of the influence of the global market which is more streamlined in terms of product standard and high competition. Figure 3 presents the value of fish exports by product type.

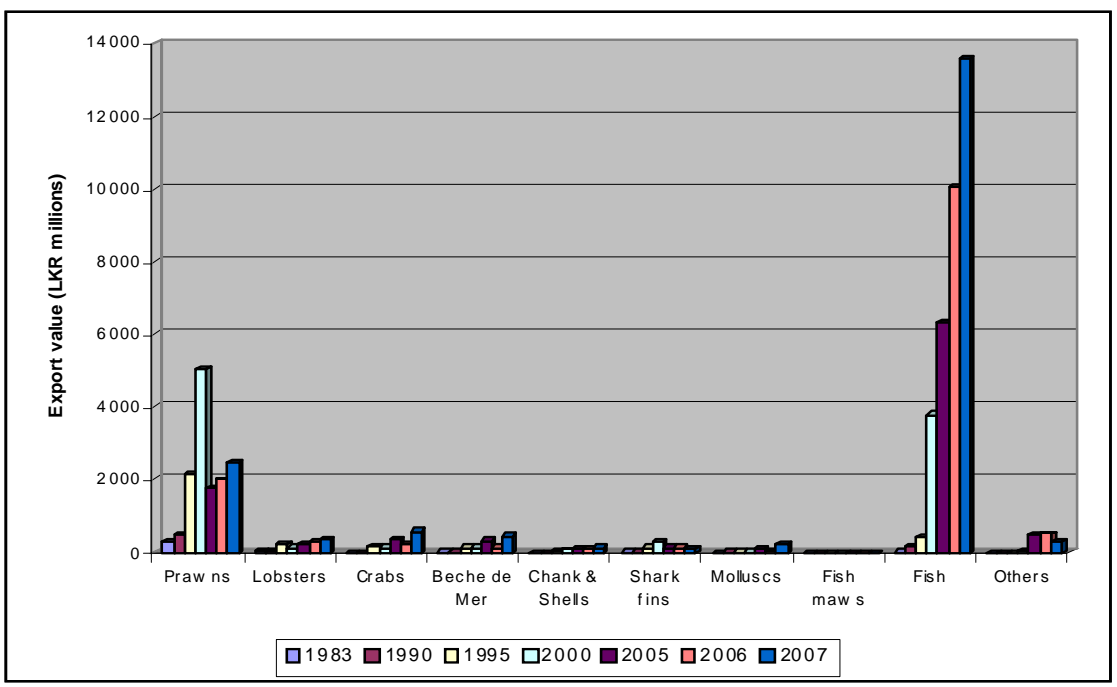

Figure 3: Value of fish and fish products exports, 1983-2007

Source: Ministry of Fisheries and Aquatic Resource Development

\section{High value product}

The product of this segment is finally consumed in the domestic market and lower value export market. These products fetched a good price but are 
highly species oriented. The supply chain followed in this segment starts from the landing center where procurement is made the collection point in this case is the middlemen followed by the agents and the wholesaler at the regional market which then feeds it to the distribution channel comprising of the retailers. The product of this segment undergoes minimal processing. The sorting of the product is taken up by the middlemen who further also takes up temporary freezing arrangements and arrangement for the transportation to the regional market. The profit margins for this segment is moderate to high depending upon the species of catch, quality of the catch, size of the catch, present market demand.

\section{Average value product}

The products of this segment are consumed in the local market or the regional market. Apart from local consumption, these products also meet the industrial requirement for poultry feed and other ancillary units. The profit margin in this segment is lower compared to high value market.

\section{Low value product}

This product segment caters to the small fishers of very low economic value. The prices of the products are determined the local players. As it is a product of low value, the chain is a diffused chain and is dominated by the fishermen. The direct buyers/ retail agents are the important players in this segment. The profit margin is very low. The general supply chain of this product segment initiates at the landing center and directly ends up with the final consumers.

Figure 4 and 5 describe the value chain of the product (fish) from landing centers (except the case of culture of fish) to the final consumer taking into consideration the entire gamut of service providers at various levels of the chain, the value addition done, the service provided or the subsequent value added to the product before consumption in lieu of the profit, from the operations undertaken by them (OXFAM, 2005).

Fishing sector constitutes a value chain composed of two different phases forming a system; the capture (food fish)/culture (prawn and shrimp) is the primary phase and the industrial or secondary phase. The industrial phase of food fish aquaculture composed of three cycles; first cycle is freezing the second cycle involves physical processing that makes it possible to obtain a standard frozen product and third cycle is production of processed foods. 

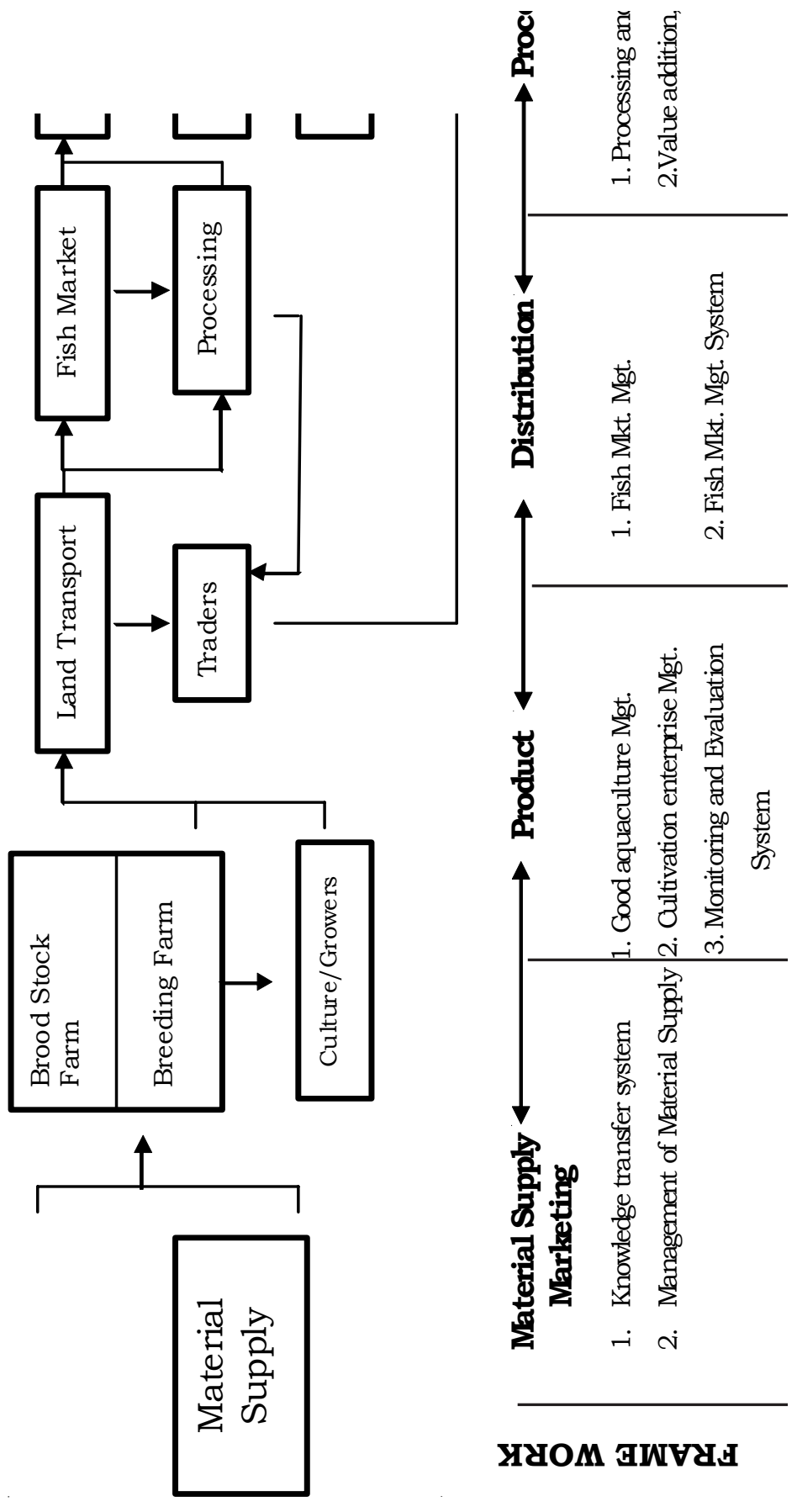

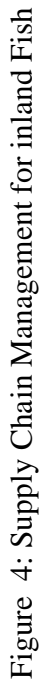




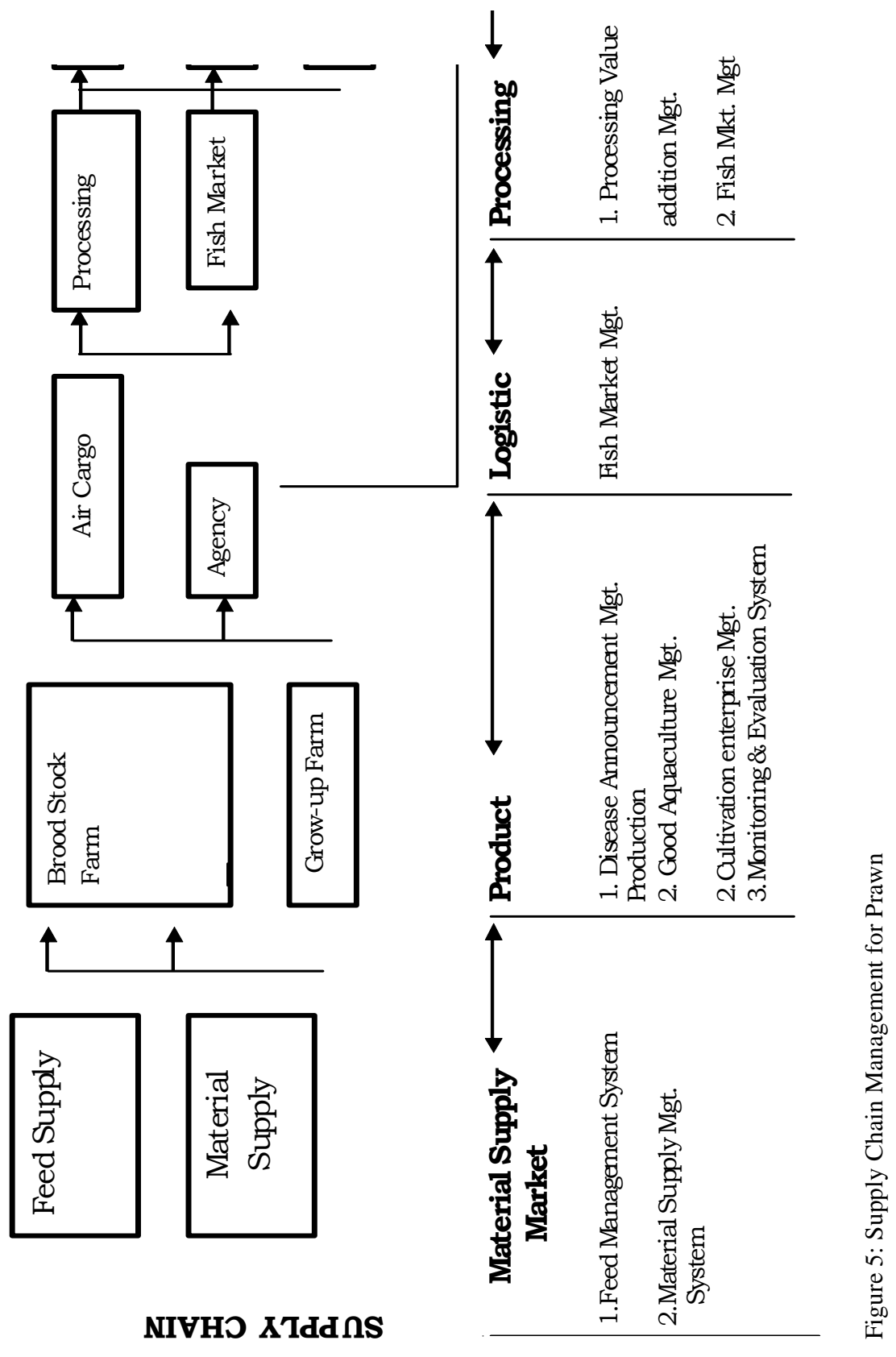




\section{Dynamics within the supply chain}

Both explicit and implicit dynamics of the supply chain allows gaining insight into the linkages between the players as well as interdependencies and systems and processes in vogue

\section{Socio-cultural}

Fishers have settled in the adjacent villages to the main fishing grounds. Characteristics of fishers divide them into two main groups such as fulltime and part time. Especially the fishers organized around seasonal tanks, they are earning income during rainy season and rest of the period they are working as laborers or farmers. There is an informal system of sharing the fishing rights. Members of the fisheries cooperative have fishing rights and access have been denied for others.

\section{Economic}

Informal mechanisms govern the fishermen's economy even today. But in contrast prawn farmers are utilizing more formalized credit systems. "PatronClient" is common among aquaculture fishers where the patron provides credit without any records and collaterals. Money is also advanced for repairs of fishing gear and boats, special occasions, health care, etc. The trade is entirely without documentation and written records. The prices, though determined at the auctions, are not paid on the spot. The payments normally take place at the end of the day or the next day. Record keeping is very poor and mislead the transactions between fishers and traders.

The fish supply chain being highly perishable is totally dependent on the timely availability of ice-crushed/flakes for extending the keeping quality as well as the shelf life. Transport is another vital link in the supply chain. Most of the aquaculture fish is transported by road using plain trucks, which are covered and packed with ice and husk (banana stem) in a manner that it sufficient for the entire duration of the journey which ranges from few hours to few days. Transportation of cultured prawn and shrimp is competently carried out through insulated wagons and the products are mainly prepared for export market. The quality management process starting from farm to the factory is essential for that.

\section{Gender}

The women have a high involvement in the ancillary support services but the exploitation by the dominant players in terms of wages is prevented. They have limited or negligible say in decision-making process as the entire 
process and procedures in the chain is highly male dominated. Typically women are entrusted with the role of fish handling and processing.

\section{Stakeholders}

The important stakeholders who are associated with the value chain can be divided into 3 categories (Table 5).

Table 5: Stakeholders existing in value chain

\begin{tabular}{|l|l|l|}
\hline Subsistence Livelihood & Economic & Conservation \\
\hline Traditional fishermen & Middlemen and wholesalers & Government \\
\hline Laborers & Exporters and processing units & $\begin{array}{l}\text { Non Governmental } \\
\text { Organizations and other }\end{array}$ \\
\hline Farmers & Craft owners & Individuals \\
\hline Ancillary service provider & Other service providers & \\
\hline Vendors & & \\
\hline
\end{tabular}

Source: field survey, February 2009

People included into subsistence category comprises of poor fishermen whose entire livelihood comes from aquaculture. In the fishery value chain the industry/ processors are on the top. The scale of operation cost of capital employed and competition at the global level is very high. This segment caters both to the domestic retail market as well as to the requirement of the processing plants and exporters. The institutions belongs to conservation category promotes conservation ideology and is against destructive practices that are not in harmony with and create ecological imbalance.

\section{BCG Matrix}

The cash cows of the fishery industry are high value products meant for the domestic market. They show the attribute of yielding a constant profit over the period of years. The contribution of the product line of this segment has been more or less regular. Cash cows are the stable products with an established value chain and a stable return pattern. The players of the value chain are certain about the profit margin and the sharing ratios are normally fixed and acceptable. Prawn and Tilapia belongs to this category (Table 6). Stars on the inland fishery are the export value products as the product line produces exemplary profit. Yet, the international markets for theses product 
lines are not fully explored. There is a vast potential in this segment to grow and yield a higher annual turn over. Catfish (local species), carps and freshwater prawn can be considered as stars in Sri Lankan inland fish industry. The "Question mark" of the fishery sector are the products that do not have a defined market. It is being traded on a price that may not be the true representative of its value. This can be attributed to the reason that the market potential for theses products is still undefined and unexplored. It has the potential to turn into the "stars" if proper investment and marketing intelligence is employed in it. At present, these products are traded at a decent profit and the demand of the product line is sufficient enough to cover the supplies and at times is beyond the supplies too. Existing examples are catfish (local) mud crab and green mussels. The dogs of inland fishery are the low value products that include small fishes, crabs prawns, etc., which are low on demand parameters. The product nature of this segment is of the type that inhibits the increase in the profit margin. The growth potential of this segment is very limited until and unless some new technology is introduced which changes product nature completely.

Table 6: Income from sale to the players in BCG matrix

\begin{tabular}{|l|c|c|c|}
\hline Species & $\begin{array}{l}\text { Price in the final } \\
\text { market (LKR) }\end{array}$ & $\begin{array}{l}\text { Income to the } \\
\text { fishermen (LKR) }\end{array}$ & $\begin{array}{l}\text { Income to the } \\
\text { middlemen } \\
\text { (LKR) }\end{array}$ \\
\hline Prawn & $600.00-700.00$ & $250.00-300.00$ & $100.00-150.00$ \\
\hline Tilapia & $150.00-170.00$ & $100.00-140.00$ & $40.00-50.00$ \\
\hline Catfish (local) & $180.00-200.00$ & $120.00-130.00$ & $50.00-60.00$ \\
\hline Carps & $100.00-110.00$ & $60.00-80.00$ & $20.00-30.00$ \\
\hline Fresh water prawn & $350.00-400.00$ & $250.00-300.00$ & $200.00-300.00$ \\
\hline Mud crab & $650.00-800.00$ & $400.00-500.00$ & $250.00-300.00$ \\
\hline Green mussel & $450.00-500.00$ & $300.00-400.00$ & $150.00-200.00$ \\
\hline Small fishes & $60.00-80.00$ & $30.00-40.00$ & $20.00-30.00$ \\
\hline
\end{tabular}

\section{Fish bone analysis}

Fish bone analysis or "Ishikawa diagram" (Ishikawa, 1990) provides a systematic way of looking at effects and the causes that create or contribute to those effects. It helps to visually display many potential causes for a specific problem or effect. Fish bone analysis has enhanced the understanding of livelihood of the fishermen (Figure 6). Exploitation of the fishermen is 
prevalent in food fish aquaculture by the other dominant actors of the supply chain. The oligopoly of the few middlemen has distorted the profitability balance in their favor. Poor market awareness is common and fishers have to depend on the price set by the middlemen. Poor bargaining power of the fishermen leads to lower the profit margins.
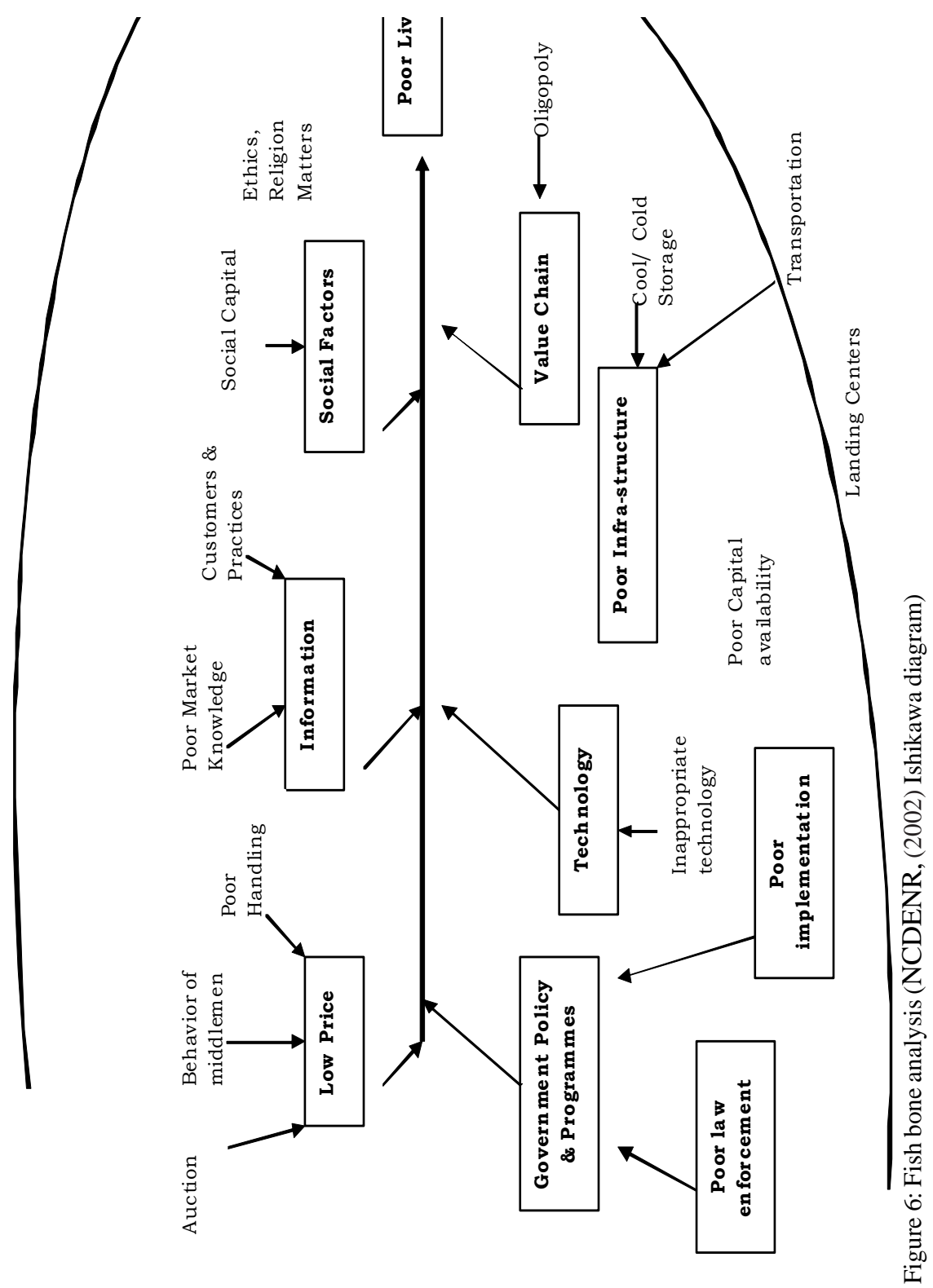
-Fish bone analysis has enhanced the understanding of livelihood of the fishermen.

-Exploitation of the Fishermen is prevalent in Food fish aquaculture by the other dominant actors of the supply chain.

-The Oligopoly of the few middlemen has distorted the profitability balance in their favor.

-Poor market awareness is common and Fishermen have to depend on the price set by the middlemen.

-Poor bargaining power of the Fishermen lends to lower the profit margins.

-The due diligence of the Fisherman is severely downsized because of the non-existence information channels, on prices and demand of the various species in the bigger markets.

-The lack of adequate infrastructure like chilling plants, Jetty, weighing facility, ice supply, roads and insulated wagons for transport etc., had forced the phenomenon of "Distress Selling"

-This has been one of the crucial factors limiting the profitability of the fishermen.

-Fishing technology used by the fisherman is outdated the crafts with or with out motors are a common parlance. In general, fishers are using traditional methods.

-The low pricing of the catch is prevalent and avoid new entrants to the industry.

-The traditional customers and traditional ways come in conflict with the modern, technology and thus impede the development of the fishermen.

-Inefficient execution and implementation of government policies and programmes in a way has delayed the development of the Fishermen.

\section{Conclusion}

The research on the value chain of fishing explained the processes and procedures that are in vogue in the traditional value chain. The search helped in analyzing the roles and responsibilities of the various players and at the same time looked in emphatically into the problems of the various players. The control over the entire supply chain is in the hands of few large players i.e. traders and exporters. There are large numbers of "intermediaries" within the supply chain who add to the prices of the species without adding "value" 
to the extent of the final price realized by end consumers. Only about 25-30 $\%$ goes to the first leg of the supply chain. Notable exception observed being for high value products like prawns and shrimps where intermediaries are less in number and fishermen fetched between $70-75 \%$ of the consumer price.

The logistical infrastructure is week except for prawn aquaculture. Prawn and shrimp farming facilities are built up with private sector investments and designed to meet international requirements. Efforts being made by the National Aquaculture Development Authority together with Asian Development Bank to improve the logistical facilities including strengthening fish breeding and research centers, marketing facilities, chilling centers, processing centers and training centers. There is complete absence of insulated vehicles except those owned by the exporters, which have an adverse effect on the keeping quality. The same is true for timely availability of transportation vehicles though few individual traders are resorting to use their own vehicles. Supply chain is handled by the few hands belong to the landing centers and which leads to create entry barriers to others.

The research findings point out to the presence of patron-client relationship through out the supply chain. The absence of clear policy on the rights of fishing grounds and natural resources from livelihood perspective and well laid out guidelines and regulations for its enforcement is essential. This is very important to strengthen and perpetuate the patron-client relationship. The supply of financial resources for the further investment is highly dependent on informal financial sources such as village money lenders, boat owners (patron-client) and agents. There is prevalence of "Advance mortgaging of the catch". The fishermen are loaned money by the traders / exporters who in turn have absolute right over the catch in essence the fishermen lose right over their catch even before venturing into the sea.

The regional markets are governed by the local demand. Preference for fish species in the rural markets depends on availability in rural markets. Majority of the wholesale and regional markets function as commission agents on behalf of the suppliers from the landing centers with a few exceptions. The payment system adopted at the regional market is cash intermingled with credit. Regular mechanisms adopted at the regional market is cash intermingled with credit. Regular mechanisms were found weak, reasons being manifold from the absence of adequate infrastructural facilities and unstable political power. Legal procedures for the international market and it's implementation are comparably well functioning. Community managed fishery rules and regulations are helping to utilize the resources even among the participants. 
Moreover, community management is more focused on mesh size control, ban on motorized boats, mangrove destruction and illegal fishing. In general, fisher women serve as a house wife. Women's role in handling and processing is vital to the industry. Especially, handling, grading and small-scale drying and smoking are performed by their hands. Female labor has significant impact on prawn and shrimp processing factories through they have little involvement in decision making. The market practices are not suited to their convenience and lack of education, infrastructure facilities and basic amenities make them vulnerable to exploitation in all forms. The marginalization of women increases with every step of the value chain with complete exclusion at the top end.

\section{Recommendations}

\section{Policy implications}

Policy advocacy in terms of the strict enforcement of regulatory mechanisms should be organized by the regulatory bodies. Village based or reservoir based fish marketing societies with processing facilities is vital to uplift the rural economy. Strengthen the infrastructure facilities, such as transportation (insulated wagons), ice plants, market places, cold storage, processing facilities and micro finance facilities are very important amenities that aquaculture fishers are not enjoying. Establishment of transport and streamlined auction mechanism under supervision of a committee consisting of fishermen's representatives, trade representatives and government officials is an urgent need. Advocacy for establishment of community property rights on reservoir or tank basis is a must.

\section{Short term strengthening of the existing supply chain}

There is a essential need to provide marketing "know How" to fishers, traders, agents and distributors. Reservoir or tank based "fish marketing societies" should strengthen with micro-finance, basic infrastructure and skills. National Aquaculture Development Authority should ensure that one of the mandates for their programme should be the training of selected group of fishermen in all marketing aspects and establishing capacities of inland fishing community. Special attention has to be provided for exporters, processors and fishers engaged in international seafood market where they need skills on international marketing. Establishment of market intelligence system for both domestic and export market is an essential need of the industry. Lack of dynamic market intelligence is one of the major constraints affecting adequate returns to fishermen. 


\section{Long term strengthening the existing supply chain}

Government or NAQDA's attention has paid to the incipient development of new fishery activities. Direct investment and or transfer of technology, technical assistance, equipment and input supply for breeding of high yielding species and other species, taking advantage of the environmental conditions of the water bodies, especially reservoirs and seasonal tanks. Transfer of technology, technical assistance and equipment and input supply for aquaculture activities in the coastal and inland waters. Huge potentials do exist in coastal aquaculture plus the brackish water fish farming around the island.

Transfer of technology, technical assistance and equipment and input supply for fish producing for both domestic and international markets are very important needs. Market demand is high for fish and fishery products processed using traditional food preservation methods and ethnic markets should widely open. The important areas to focused on international market are target for more value added products rather then raw material supply, re-processing of the products from neighbors such as Maldives, India, Vietnam and Bangladesh and export to higher value markets, searching for new niche markets and cater to ethnic Sri Lankan markets and research on new product development.

\section{References}

Haputanthri, S., Perera, P.A.J.C. and Vidanage, S.P. (2001) Development of ornamental fish production and culture for increased export earnings and employment opportunities. Unpublished report of NARA, Colombo 15, Sri Lanka. pp. 49.

Ishikawa, K. (1990) (Translator: J. H. Loftus); Introduction to Quality Control; http://en.wikipedia.org/wiki/Ishikawa_diagram, Accessed on $20^{\text {th }}$ January 2009, pp. 448.

Mercer, D.A. (1993) Two Decade Test of Product Life Cycle Theory pp 269-274, British Journal of Management, v. 4, pp. 269-274.

National Aquaculture Development Authority of Sri Lanka (2009) Annual report, National Aquaculture Development Authority of Sri Lanka, Colombo, Sri Lanka

North Carolina Department of Environment and Natural Resources (NCDENR) (2002) Fish bone diagram: A problem analysis tool, , http:/ /quality.enr.state.nc.us/tools/fishbone.htm, Accessed on $3^{\text {rd }}$ November 2008. 
Sanyal, N. and McLaughlin, W.J. (1993) The link between hunting goals and strategy and harvest outcome. Leisure Sciences v. 15(3), pp. 189204.

Siriwardena, P.P.G.S.N. (1999) Shrimp culture in Sri Lanka: The benefits, problems and constraints associated with the development and management and responses to address problems. Bangkok FAO Technical Consultation on Policies for Sustainable Shrimp Culture. FAO Fisheries Report No. 572, pp. 99-110.

Siriwardena, P.P.G.S.N. and Jayakody, D.S. (2003) Aquaculture technologies and fishing practices of Sri Lanka. Report submitted to ICLARM on the Strategies and options for increasing and sustaining fisheries and aquaculture production to benefit poor households in Asia, ADB - RETA 5945 Project. Sri Lanka 